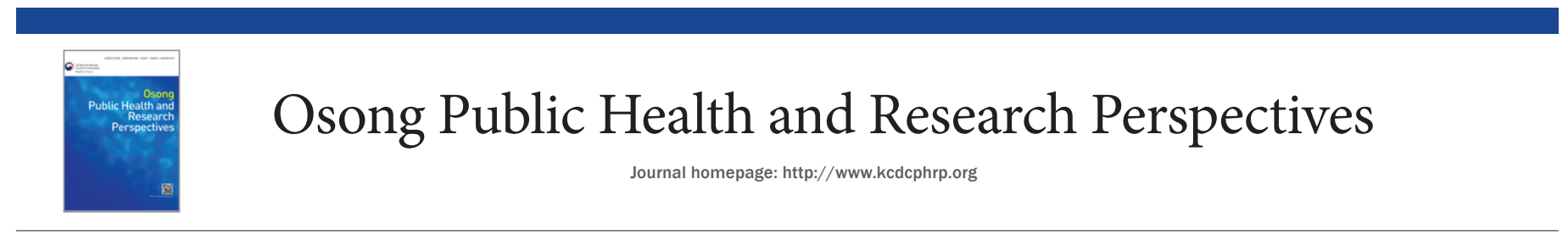

Editorial

\title{
Depression Status in Korea
}

\author{
Soo Kyung Koo* \\ Division of Intractable Diseases, Center for Biomedical Sciences, Korea National Institute of Health, Cheongju, Korea
}

https://doi.org/10.24171/j.phrp.2018.9.4.01 pISSN 2210-9099 eISSN 2233-6052
Depression (major depressive disorder or clinical depression) is a common mood disorder that can cause serious consequences. Depression is defined as a medical condition that lasts for more than 2 consecutive weeks including sadness, loss of interest, changes in appetite, sleeping problems, fatigue, purposeless physical activity or slowed movements, feeling worthless or guilty, difficulty thinking and thoughts of suicide. It is distinguished from temporal fluctuations of natural emotions, or from the challenges experienced in everyday life [1].

Environmental, psychological, and genetic factors may all be involved in complex interactions which can result in depression [2]. Depression is more likely to occur if there has been a recent life changing event, family history, prescribed medication, or a health problem. Individuals who take illegal drugs are more prone to depression than people who do not.

Globally, depression has been reported to have affected more than 300 million people. The World Health Organization reports that depression is the leading cause of disability as measured by years lived with disability, and the $4^{\text {th }}$ leading contributor to the global burden of disease [3]. In 2015, depression was a top cause of age-specific disability-adjusted life year ( $3^{\text {rd }}$ in age category $15-19$ years, $2^{\text {nd }}$ in 20-24 years old, $4^{\text {th }}$ in $25-39$ years old, $5^{\text {th }}$ in $40-44$ years old, and $6^{\text {th }}$ in $45-54$ years old) [4].

Depression is also reported to be associated with suicide. It is believed that $50 \%$ of all suicides are related to depression [5], and $2 \%$ to $9 \%$ [6], or $15 \%$ [7] of people diagnosed or treated with depression will die from suicide. It is also known that depression is a contributing factor to the prognosis of chronic diseases. According to Moussavi et al [8], some depression had adverse effects on health scores rather than on chronic disease, and depression and chronic illness together showed a worse health outcome than any other combination of chronic diseases.

Over the last 50 years, Korea has undergone unprecedented economic growth and changes in social values. As a result, mental health problems have become a national issue. Korea has the $2^{\text {nd }}$ highest suicide mortality rate $(25.8$ per 100,000 population) out of the country members within the Organisation for Economic Co-operation and Development [9]. An epidemiological survey on mental health conducted every 5 years reported a gradual increase in the prevalence of depression (2001, 4.0\%; 2006, 5.6\%; 2011, 6.7\%) [10,11]. A cluster randomized trial study conducted in Philadelphia, USA reported that the greening of vacant land showed a positive effect on the mental health of residents [12]. This suggests that mental health may be improved by community specific policy efforts to improve the local environment. Based upon this evidence, data from national and regional surveys of mental health status will aid mental health policy design.

The current issue of Osong Public Health and Research Perspectives includes a study of "Regional differences of mental health status and associated factors: based on the community health survey ". This study [13] used data obtained from the 2016 Community Health Survey (CHS). CHS was performed by the Korea Centers for Disease Control and Prevention (KCDC) and contained data from 224,421 people who over 19 years of age [13]. Lim [13] showed independent lifestyle and health status variables had statistically significant effects on stress or depression and found associations of several risk factors with depression in both urban and rural areas. These data are expected to be used for establishing mental health policies according to local characteristics.

*Corresponding author: Soo Kyung Koo

Division of Intractable Diseases, Center for Biomedical Sciences, Korea National Institute of Health, Cheongju, Korea

E-mail: skkoo@korea.kr

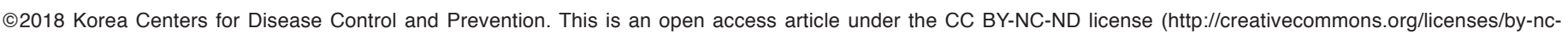
$\mathrm{nd} / 4.0 /)$. 


\section{Conflicts of Interest}

The author declared no conflicts of interest.

\section{References}

[1] American Psychiatric association [Internet]. Depression. [cited 2018 Aug 1]. Available from: https://www.psychiatry.org/patients-families/ depression/what-is-depression.

[2] Subbarao A, Rhee SH, Young S, et al. Common genetic and environmental influences on major depressive disorder and conduct disorder, J Abnorm Child Psychol 2008;36(3):433-44.

[3] World Health Organization [Internet]. Global Health Estimates 2016: Disease burden by cause, age, sex, by country and by region, 2000-2016. Geneva (Switzerland): 2018. Available from: http://www.portal.pmnch. org/healthinfo/global_burden_disease/estimates/en/.

[4] GBD 2015 DALYs and HALE collaborators, Global, regional, and national disability-adjusted life-years (DALYs) for 315 diseases and injuries and healthy life expectancy (HALE), 1990-2015: a systematic analysis for the global burden of disease study 2015. Lancet 2016;388:1603-58.
[5] Breitbart W. Cancer pain and suicide. In: Foley K, Bonica JJ, Ventafridda V, eds. Advances in Pain Research and Therapy: Second International Congress on Cancer Pain, Vol. 16. New York (NY): Raven Press; 1990. p. 399-412.

[6] Bostwick JM, Pankratz VS. Affective Disorders and Suicide Risk: A Reexamination. Am J Psychiatry 2000;157(12):1925-32.

[7] Simon GE, VonKorff M. Suicide mortality among patients treated for depression in an insured population. Am J Epidemiol 1998;147(2):155-60.

[8] Moussavi S, Chatterji S, Verdes E, et al. Depression, chronic diseases, and decrements in health: results from the World Health Surveys. Lancet 2007;370(9590):851-8.

[9] OECD [Internet]. Suicide rates. 2018 [cited 2018 Aug 1]. Available from: http://data.oecd.org/healthstat/suicide-rates.htm.

[10] Cho MJ, Lee JY. Epidemiology of depressive disorders in Korea. Psychiatry Investig 2005;2(1):22-7.

[11] Cho MJ, Seong SJ, Park JE, et al. Prevalence and correlates of DSMIV mental disorders in South Korea adults: the Korean epidemiologic catchment area study 2011. Psychiatry Investig 2015;12(2):164-70.

[12] South EC, Hohl BC, Kondo MC, et al. Effect of greening vacant land on mental health of community-dwelling adults: a luster randomized trial. JAMA Netw Open 2018;1(3):e180298.

[13] Lim JH. Regional Differences of Mental Health Status and Associated Factors: Based on the Community Health Survey. Osong Public Health Res Perspect 2018;9(4):175-84. 